\title{
UNIVERSITYOF
}

FORWARD

THINKING

WESTMINSTER用

WestminsterResearch

http://www.westminster.ac.uk/westminsterresearch

\section{Drama Out of a Crisis: A Celebration of Play for Today}

Wyver, John

This is a copy of the accepted author manuscript of the following article: Wyver, John 2021. Drama Out of a Crisis: A Celebration of Play for Today. Critical Studies in

Television: The International Journal of Television Studies. 16 (1), pp. 62-68.

https://doi.org/10.1177/1749602020982748 . The final definitive version is available from the publisher Sage at:

https://doi.org/10.1177/1749602020982748

(C) The Author(s) 2021

The WestminsterResearch online digital archive at the University of Westminster aims to make the research output of the University available to a wider audience. Copyright and Moral Rights remain with the authors and/or copyright owners. 


\section{Drama Out of a Crisis: A Celebration of Play for Today}

John Wyver, University of Westminster / Illuminations

When BBC Arts invited me in February 2019 to produce a documentary to mark the fiftieth anniversary of Play for Today, BBC1's series of single dramas that ran from 1970 to 1984 , I determined that I would ground the series in the social and political context of the time. I was also certain that the film must demonstrate a rigorous respect for the archival recordings of the series. But I wanted also to disrupt certain of the conventions of the classical talking-heads-and-clips format of programmes about film and television history. Following some fifteen months, on and off, of research and viewing, four days filming of interviews just before the Covid-19 lockdown in March, and a 10-week edit, the 89-minute Drama Out of a Crisis: A Celebration of Play for Today was broadcast on BBC Four on 10 October 2020. ${ }^{1}$ The film has been well-received and it contributed to a cluster of anniversary activities including a run of BBC Four repeats, a BBC Canvas exhibition, the release of BFI Blu-ray box-set of seven Play for Today titles, a BFI Southbank series of screenings that was postponed and ultimately severely curtailed, and an online academic conference. ${ }^{2}$

Throughout the post-production process collaborations with editor Todd MacDonald and graphic designer lan Cross were key to the final form of the documentary. As the three of us worked intensely with the stuff of television history, with the archival extracts in digital form, but also with photographs, production files and scripts, together with Radio Times billings and press clippings, and indeed with the memories of practitioners, the film increasingly came to foreground two closely related aspects of the materiality of television. As this essay details, Drama Out of a Crisis exposes the materiality of production processes, both nearly fifty years ago and today, at the same time as it showcases and manipulates the materiality of the archival traces left by Play for Today. I want also to make the case that, while demonstrating our continued respect for all that stuff, we succeeded, to a degree at least, in opening up the screen language of 
documentaries about the past of the moving image so as to make what feels like a film for today.

\section{Out of the archive}

One of the challenges of Drama Out of a Crisis to the conventions of many historical documentaries is that it uses both moving image archive and stills in ways that are denser and richer than many historical documentaries. The film features an extensive range of elements, often using only a few frames from a programme, and it frequently employs split-screen techniques so that there are two, three or even more elements running simultaneously. At the same time a number of comparatively lengthy elements from key plays are included, and these run uninterrupted (and just as they are in the original, with no internal cuts) for two minutes or more.

At the start of my research I committed to trying to watch, so as potentially to choose clips from, each and every one of the some 270 extant Plays for Today ${ }^{3}$. While I fell short of achieving this I had watched more than 200 before finishing the documentary. One fundamental principle of working with extracts was the importance of retaining in the final film their original aspect ratio. All Plays for Today, whether made on film or tape, were shot and mastered with a 4:3 frame ratio. Almost all television today is made with a wider $16: 9$ ratio and far too often programme makers simply screen off the top and bottom of $4: 3$ material so that it fills the 16:9 frame. Situating 4:3 sequences in the centre of a 16:9 frame opens up empty areas to their left and right. To counter this graphic designer lan Cross created a palette of 'textures' of subtle patterns and colours to fill these areas. ${ }^{4}$

Almost all of the moving image archive, from both the plays and films themselves and from contextual material illustrating social and political themes comes from BBC Archives. ${ }^{5}$ It was a privilege being able to work so freely and so creatively with the rich resources of the BBC Archives, and the programme was able to take the form it does because of two operational databases that underpin the operation of BBC Archives. 
The first of these is 'Archive Search' which indexes all of the existing materials and contains available metadata (of varying detail) and, where they exist, low resolution digital files (that is, of not sufficient quality to be broadcast) that can be directly downloaded by an authorised user. If a programme we wanted to view had not yet been digitised we were able to request this, and for tape masters the 'low res' was made in short order. For just a handful of dramas for which only film masters existed we needed to have made new high definition masters.

Equipped with the low res files we were able to begin to make choices of shots and sequences to edit with, and at this stage in the production process the other database, 'Digital Archive', proved to be transformative. Digital Archive facilitates the authorised user to access directly high resolution broadcast masters and either to download a very chunky file of a full programme or to identify via the interface a specific sequence and then to request just this part of the programme. Usually within a half hour or so you receive an e-mail with a download link for just the section you identified. For those of us old enough to have spent hours and days identifying clips that one wanted to be transferred from film to tape by 'papering up' film prints with slips inserted into unwieldy reels on a Steenbeck editing table this is a truly significant technological advance. Even in recent years ordering and securing archive clips from tape masters has been time-consuming and prone to error, so to work instantly on an automated system like this feels extraordinarily liberating.

Archive Search and Digital Archive combined meant that Todd and I could work with a far wider range of $\mathrm{BBC}$ archive than we might otherwise have had time and resources to do, and the visual style of the finished film was made possible and to a significant degree shaped by these forms of archive access. More obviously perhaps than in other contexts the archive here was far from a neutral repository but rather a creative collaborator. But it was not only archival access that made possible the style and approach of the programme possible. We were also able to work with such a range of images because, first, all of the films are owned by BBC Television and we had direct access to masters, and second, because the 
documentary uses the extracts 'for the purpose of criticism or review' and always with appropriate acknowledgement. As such, under the 'fair dealing' provisions of section 30 of the Copyright, Designs and Patents Act 1988 , the integration of the clips does not infringe any copyright in the work. And so we have been able to draw on such a wide range of extracts without needing to secure extensive permissions or pay prohibitive fees.

This legislation, however, is specific to the United Kingdom and would not apply were we to distribute the film and its extracts abroad. Moreover, as a BBC commission the film can employ all of the extracts (and also BBC photos) without a direct charge to the budget. But if we wished to release a DVD or make the documentary available on a commercial streaming service we would be required (not unreasonably) to negotiate fees for the extracts and images, and the return would almost certainly not make this viable. As a consequence it is extremely unlikely that Drama out of a Crisis will have a life beyond its screenings on BBC Four and the year that it will stay on BBC iPlayer.

\section{The graphics}

Thoughtful, integrated graphic design can add immeasurably to a documentary, although too often it can be one of the last elements to be considered, once almost everything else was in place. Drama Out of a Crisis required an overall design that would contribute to situating the archive and the issues in their historical moment, and help bring together the drama with the political and social world of the 1970s as well as with the production context in which the plays and films of the series were made. The original treatment conceived the film as structured in chapters, each of would need headings, and it also seemed likely that the opening would graphics-heavy so as to communicate basic facts about the series as well as the breadth of the commissions and the extraordinary range of contributors both before and behind the cameras.

lan Cross started our discussions with mood boards culled from Pinterest and elsewhere of graphic elements from the 1960s and '70s book covers, especially Penguins, were one important reference, along 
with record sleeves, posters and other traces of the time. We also drew on the distinctive Play for Today title sequences, of which there were seven in all, each with individual styles and typography. Just as important to the mix were printed materials related to the original series: scripts and production paperwork, publicity materials, and Radio Times features and billings. All of these feature in lan's layerings and composites and animated scribblings in the opening three minutes and also fed into the chapter headings. Indeed, the idea of the script as the originary element of every Play for Today became centrally important, with page layouts, punched holes, tape marks and paperclips as structuring elements, along with a typewriter typeface for caption lines identifying writers and directors on extracts and contributing a selection of credits for each interviewee.

One other crucial component was the materiality of both filmmaking and recording to videotape, so that throughout the graphics we used edge numbers and leaders from film prints, studio clocks and ident boards, and also 'glitches' like film 'flashes' and image distortions and break-ups that open up the technical processes of television production. Closely related to this was our use of moving image records of the electronic studio in operation in the 1960s and 1970s. A behind-the-scenes Monitor film Making The Bedmakers was an invaluable source to illustrate the production context for drama from which producer Tony Garnett and director Ken Loach aspired to escape with their ground-breaking slices of social realism for Play for Today's predecessor The Wednesday Play. We also drew heavily on a half-hour film made by the BBC in 1971 for young people, Behind the Scenes: A Tour Around Television Centre. And we searched, without much success, for photographs showing the making of individual Plays for Today. Documenting the operation of television drama was not a priority for the corporation's stills photographers in these years.

\section{Abstracting the interviews}

We shot 13 interviews over four days at the end of January and in the first week of February, more than a month before even the inkling of a lockdown. Elements from ten of these feature in the documentary. We 
started with the conviction that an interviewee who was a participant in whatever one is asking about will invariably contribute something significantly more than a commentator. Moreover, this extra value is not (simply) accuracy or detail or comprehensiveness, but something much more intangible: authenticity, or texture, or what some theorists might identify as 'atmosphere'. The featured interviews as a consequence have qualities that exceed the information or ideas they convey, with the ways in which contributors use their hands, how they smile and sit and shrug, and indeed how for a moment or two they sit in silence are fragments of the history with which the film engages.

It was also important to achieve a consistent, meant style across the interviews, with the focus centred on the contributors and not on the surroundings of an office or living room. Abstracting them from the everyday was a way to achieve this, and so we filmed them in a small central London studio against a range of colour rolls as backgrounds for our main " $A$ " camera. The choice of which hue backed which interviewee was largely random and the range was dictated by what had been left over from previous shoots in the space. Extending the idea of foregrounding of production technologies and techniques, wwe set a second, "B" camera that revealed our own studio set-up, and we also requested that each interviewee use a clapperboard to begin the recording.

In cutting and shaping the material we paid attention to the expressive and performative qualities of the interviews as well as what was actually being said. Todd MacDonald also developed distinctive and innovative techniques in the cutting of the interviews. Because they were shot to a high technical standard with a $4 \mathrm{~K}$ camera, in addition to editing between moments, we could cut "into" the images of both cameras. The pictures were recorded at such a high resolution that we could digitally find new framings without any noticeable loss of quality for our HD master. So Todd was able to re-position our subjects and conjure up close-ups from mid-shots, even though both $A$ and $B$ cameras had held static frames throughout the filming. The result is dynamic and visually rich, and was used to bring emphasis to and enhance the impact of a spoken 
contribution, but it also draws attention to our own production process, reminding the viewer that all of this is a construction, an interpretation.

\section{Style and self-reflexivity}

Having spent many years both producing and researching arts documentaries, including those incorporating archival moving images, my conviction on setting out to make Drama Out of a Crisis was that such films employed staid and static screen languages that had hardly changed in five decades. Their frames were invariably filled with single images and their intention was to offer to the viewer supposedly direct access to a world in front of the camera. Kenneth Clark was doing this in Civilisation (1969) more than fifty years ago, and Simon Schama in The Romantics and Us (2020) is still doing much the same. Nor in most arts documentaries made for television is there any attempt to acknowledge the processes of mediation, or a concern to offer any sense of selfreflexive presentation. As we looked for alternatives Todd MacDonald and I recognised our fascination with the ways in which during lockdown screen performance especially, but other media offerings too, quickly developed sophisticated split-screen languages, multiplying image streams within the overall frame and making creative juxtapositions across and within individual elements. Moving image history features a multitude of earlier but somehow still marginal explorations of the languages of splitscreen. At the same time it seemed that, in large part because of the ubiquity of Zoom, Teams and similar interfaces in all of our lives under lockdown, split-screen 'spatial montages' had become mainstream in new ways, and we were intrigued to explore whether we could bring something of this style to Drama Out of a Crisis.

The split-screen sequences in the documentary serve a number of purposes. They permit references to a much wider range of archive material, and a much greater number of plays, than would have been possible in a straightforward linear edit of the same duration. They offer the possibility of compressing and perhaps even enhancing a lengthy archive sequence, as the film does to relate the story of Shadows on our 
Skin and with the ending of The Garland. They offer connections between extracts and people, offering a variation on the conventional voice-over full-frame extract so often employed, as we when Margaret Matheson and Alan Clarke, in an archive fragment, speak about Scum. At certain moments the split-screens suggest connections between people, as when an archive clip of the late Tony Garnett from some 25 years ago appears to be "listening" to Ken Loach speaking in 2020. This is then enriched with a sequence of side-by-side end title frames exemplifying the closeness of their professional relationship, to which Ken also refers in his interview. And the split-screens allowed us to adopt a playful attitude to the archive, as when an archive clip of Dennis Potter is mirrored so that he speaks either side of the mirrored title sequence of his Double Dare.

The film is visually richer, denser, more distinctive thanks to the split-screens. Taken together with the editing of the interviews and the graphics, the split-screens also achieve a deliberately self-conscious or self-reflexive style. This is a film that constantly draws attention to itself and to the processes of its production. In his 1995 book Televisuality: Style, Crisis, and Authority in American Television, the scholar John T. Caldwell identified the appearance in television programming, and especially drama, of the time of what he dubbed 'televisuality'. Earlier television, he suggested, had been content to transmit directly what was in front of a camera, whether that was a news broadcast, a sports event or a quiz show. But now television was starting to showcase its visual inventiveness and to move beyond a grounding in the idea of the relay. In her exceptional study of the BBC's 2005 classic serial Bleak House, Christine Geraghty neatly characterises Caldwell's analysis:

Increasingly, style was upfront, designed to be noticed and enjoyed, the experience itself, not just something to support the content. And, although television drama was by no means the main plank of his argument, televisuality was to be found, not only in artistic dramas aimed at a specialist audience, but in popular television series such as Hill St Blues and Miami Vice. This interest in style as 
to-be-looked-at rather than to-be-looked through was a challenge to the classic serial's more conservative tendencies throughout the 1990s.

In summary, we wanted the style of Drama Out of a Crisis to be one to-belooked-at rather than one to-be-looked-through. Such a to-be-looked-at style, however, was not intended simply an exercise in decorative contemporaneity. Our hope was, as it remains, that self-reflexivity in Drama Out of a Crisis would prompt a critical engagement with the archive, and with its politics. We intended that the film would be enjoyable, and that the extracts would prompt surprise and even shock as well as nostalgic pleasure, but ultimately we wanted the film's to-be-looked-at style to provoke viewers to question each extract and every statement.

\footnotetext{
${ }^{1}$ Key credits for Drama Out of a Crisis are:BBC Commissioning Editors Mark Bell, Emma Cahusac; director of photography Phil Cooper; graphic design lan Cross; editor Todd MacDonald; an Illuminations production for BBC. The film is available (in the UK only) on BBC iPlayer until 9 October 2021 at [url to come]. 2 [Add url of exhibition? details of box set? Credits for academic conference?] 3 Since some plays were commissioned for the series but shown without its branding whereas others were made for The Wednesday Play (1964-70) but were screened in the first season, and because some productions were broadcast first as standalone dramas but then repeated as Plays for Today, the exact number of the Play for Today canon is contested. It is generally accepted that there were just over 300 Plays for Today, of which just over no longer exist in full.

${ }^{4}$ Another aspect of our respect for the moving image archive was captioning of all of the main archive elements, detailing not only the title of each play and its date but also its writer and director. After the broadcast producer Kenith Trodd, who is interviewed in the film, argued forcefully that we should also have included a producer credit.

5 Among the exceptions are the 1960 Armchair Theatre titles, licensed from Studio Canal, and the dismaying clip of a videotape being wiped electronically, taken from ATV's 1964 documentary The Dream Machine.
} 